\title{
ОСОБЕННОСТИ ЭЛЕМЕНTHОГО СОСТАВА FILIPENDULA ULMARIA (L.) MAXIM (ROSACEAE) НА ТЕРРИТОРИИ НОВО-УРСКОГО ХВОСТОХРАНИЛИЩА В КЕМЕРОВСКОЙ ОБЛАСТИ
}

\author{
Горбатюк Екатерина Александровна', \\ kolesnikovaea@tpu.ru
}

\author{
Барановская Наталья Владимировна', \\ nata@tpu.ru
}

\author{
Жданов Вадим Алексеевич', \\ hyfrvadim@gmail.com \\ 1 Национальный исследовательский Томский политехнический университет, \\ Россия, 634050, г. Томск, пр. Ленина, 30.
}

\begin{abstract}
Актуальность исследования обусловлена необходимостью получения комплексной информации о влиянии радикальных изменений биогеохимического фона в районах распространения хвостохранилищ горнорудного производства с целью прогнозирования путей миграции токсичных компонентов.

Цель: выявление изменений в элементном составе корневой и надземной части Лабазника вязолистного (Filipéndula ulmária (L.) Maxim.) и установление индикаторных показателей техногенного влияния хвостохранилища руд Ново-Урского месторождения. Задачами исследования являются: определение коэффициентов концентраций химических элементов относительно фоновых значений, изучение особенностей пространственного распределения элементов в надземной и корневой частях лабазника вязолистного на территории хвостохранилища, установление коэффициентов аккумуляции химических элементов в корневой части лабазника вязолистного по отношению к надземной.

Методы. Сбор растительного материала произведен на флангах Ново-Урского хвостохранилища. Элементный состав лабазника вязолистного определен методом масс-спектрометрии с индуктивно связанной плазмой (ИСП-МС) в лаборатории аналитического центра «Плазма» (г. Томск) по аттестованным методикам. Обработка аналитических данных выполнялась с помощью программ Statistica (6.0) и Excel. Картосхемы распределения элементов в надземной и корневой частях лабазника вязолистного построены в программах Surfer (11) и CorelDRAW (16).

Результаты. На примере Ново-Урского хвостохранилища в Кемеровской области изучено накопление 67 химических элементов в лабазнике вязолистном. Рассчитаны коэффициенты концентраций элементов относительно фоновой точки и кларка ноосферы. Составлены геохимические ряды, отражающие избыточное накопление таких элементов, как Zn, Ba, Pb, Tl, Se, Ag, W, $\mathrm{Hg}, \mathrm{Au}, \mathrm{P}$, превышающих фоновые значения в 5 и более раз. Картосхемы пространственного распределения химических элементов в лабазнике вязолистном показали наиболее высокие концентрации элементов в районе расположения отвала переработки окисленных руд и зоны потока рассеяния. Представлены коэффициенты аккумуляции химических элементов в корневой части лабазника вязолистного по отношению к надземным. Выявлено повышенное содержание химических элементов в корнях примерно в 80 \% случаев.
\end{abstract}

\section{Ключевые слова:}

Лабазник вязолистный (Filipéndula ulmária (L.) Maxim.), химические элементы,

Ново-Урское хвостохранилище, коэффициенты концентраций, коэффициенты аккумуляции.

\section{Введение}

Разработка полиметаллических руд в 1930-70-х гг. в России привела к стихийному формированию хранилищ отходов, которые до сих пор являются источниками поступления химических элементов (Pb, Sb, Zn, Cd, As, Ni, Co) в окружающую среду. Приоритетными загрязнителями считаются As, $\mathrm{Cd}, \mathrm{Cu}, \mathrm{Hg}, \mathrm{Pb}, \mathrm{Zn}$ главным образом потому, что их рассеивание в окружающей природе происходит высокими темпами, и они являются наиболее частыми компонентами антропогенных элементохимических ассоциаций [1].

Растения повсеместно используются при оценке степени загрязнения окружающей среды благодаря высокой способности поглощения широкого ряда химических элементов [2-4]. Часть из них растения используют для жизненно необходимых обменных процессов, но с увеличением концентрации отдельные элементы вызывают токсические әффекты [5-9].
Среди изученных видов выделяется лабазник вязолистный со своей способностью накапливать большой комплекс химических элементов [10-12], что позволяет использовать его в качестве индикатора техногенного воздействия, наряду с другими растительными объектами [13-15].

Лабазник вязолистный, или таволга вязолистная (Filipéndula ulmária (L.) Maxim.), род многолетних трав, семейство розоцветные (Rosaceae) (рис. 1). Травянистое растение, высотой до 1,5-2 м, с мочковатой корневой системой и гладким простым или ветвистым стеблем. Цветет в июне-июле, цветки многочисленные мелкие, белые или светло-желтые, с сильным медовым ароматом, собранные в густые рыхлые соцветия-метелки длиной до 20 см. Плоды - коричневые семянки, созревающие в конце лета. Растение встречается в заболоченной местности, на склонах и по берегам водоемов. Имеет широкий ареал произрастания в Европе, Азии, европейской части России и на территории Западной и Восточной Сибири. 


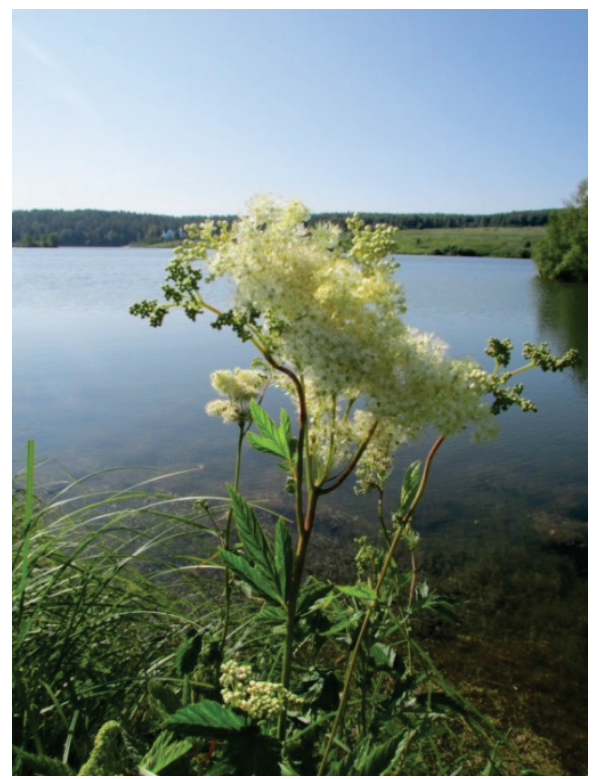

Puc. 1. Лабазник вязолистный (Filipéndula ulmária (L.) Maxim.)

Fig. 1. Meadowsweet (Filipendula ulmaria (L.) Maxim.)

Лабазник вязолистный широко используется в народной и традиционной медицине России и ряда европейских стран $[16,17]$.

\section{Объект исследования}

Хвостохранилища представляют интерес с точки зрения вторичной выработки значимых компонентов и с позиций оценки природоохранных норм [18].

Область исследуемого района представляет собой низкогорную поверхность, полого спускающуюся в сторону Западно-Сибирской низменности и резко приподнятую над Кузнецкой котловиной. Ново-Урское месторождение открыто в 1932 г. и является самым крупным месторождением группы колчеданных медно-цинковых месторождений Урского рудного поля. Расположено в п. Урск (Барит) Гурьевского района Кемеровской области [19].

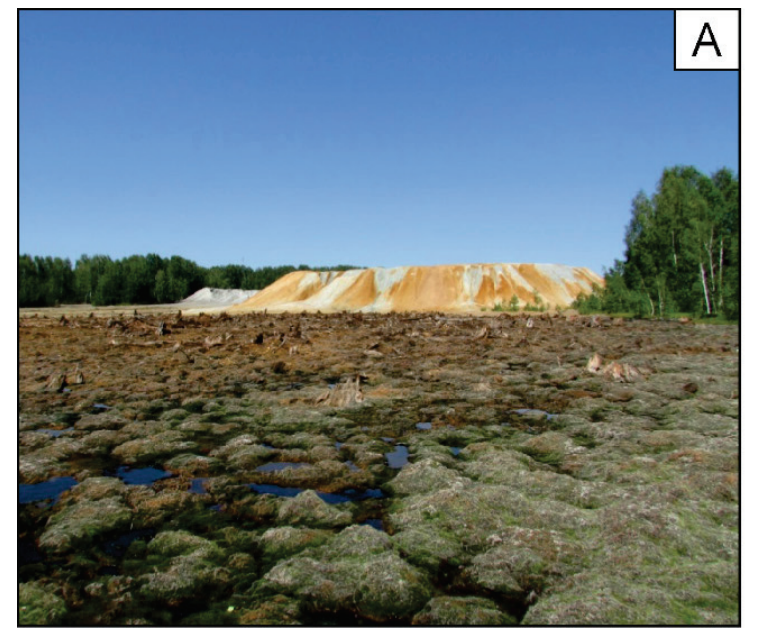

Среди сульфидных руд месторождений Урской группы зарегистрированы следующие рудные минералы: пирит, сфалерит, халькопирит, блеклая руда, галенит, арсенопирит, аргентит, золото, борнит, ковеллин, халькозин и др. Из жильных минералов наибольшим распространением пользуются: кварц, серицит, барит, кальцит и гипс. Относительно содержания меди и цинка были выявлены три промышленных сорта руд: медная и медноцинковая, цинковая, серно-колчеданная. Для извлечения золота отработаны только кварц-пиритовая и кварц-баритовая сыпучки. Другие части рудных тел сохранились нетронутыми [20,21].

Хвостохранилище содержит в своем составе отработанные первичные руды и руды зоны окисления, складированные в два насыпных отвала высотой около 10-12 м. Отвал отходов первичных руд на $50-90 \%$ сложен пиритом и практически полностью выбран для вторичной переработки, а отвал из отходов зоны окисления остался в первоначальном виде. Природный ручей, протекающий по логу хвостохранилища, дождевые и паводковые воды, дренируя материал отходов, подкисляются и распространяют незакрепленное вещество вплоть до реки Ур (приток реки Иня). Здесь происходит активное распространение растворенных форм металлов в речную сеть и подземные воды. Растительный покров, в результате воздействия кислых дренажных растворов, полностью уничтожен, и вся территория вдоль русла ручья покрыта болотными кочками [21-23] (рис. 2, А). Расположенный рядом с хвостохранилищем карьер заполнен водой и используется для ловли рыбы и купания местными жителями.

Материалом для исследования послужила надземная и корневая часть лабазника вязолистного. Образцы собраны в июле 2015 г. в сухую погоду в фазу цветения - начала плодоношения на территории Ново-Урского хвостохранилища. Сбор растения проведен в непосредственной близости к самой

Pис. 2. Общий вид Ново-Урского хвостохранилища (A), карта-схема отбора проб Лабазника вязолистного (Filipéndula ulmária (L.) Maxim.) (B)

Fig. 2. General view of Novo-Urskoe tailing (A), map-scheme of Meadowsweet (Filipendula ulmaria (L.) Maxim.) sampling (B) 
территории хвостохранилища, согласно схеме, представленной на рис. 2, Б. Условно фоновый образец отобран в районе озера Урское в 4 км к юговостоку от хвостохранилища, вдали от источника техногенного воздействия.

Каждый экземпляр растения помещался в индивидуальный стерильный пакет, далее высушивался воздушно-теневым способом без воздействия дополнительных температур для получения наиболее точных результатов [24]. Корневая часть предварительно промывалась в дистиллированной воде. Сухие пробы измельчались до мелкой крошки. Для проведения аналитических исследований брали навески по 100 мг. Элементный состав лабазника вязолистного определяли методом массспектрометрии с индуктивно связанной плазмой
(ИСП-МС) в лаборатории аналитического центра «Плазма» (г. Томск) по аттестованным методикам, с использованием государственного стандартного образца состава: лист березы ЛБ-1 (ГСО 8923-2007; CO KOOMET 0067-2008-RU). В каждой пробе определено содержание 67 химических элементов. Использование метода ИСП-МС позволяет определить минимальные значения большинства элементов, вплоть до их фонового содержания [25].

\section{Результаты исследований и их обсуждение}

Для растений наиболее опасными являются такие элементы, как $\mathrm{Cu}, \mathrm{Hg}, \mathrm{Ni}, \mathrm{Co}, \mathrm{Pb}, \mathrm{Ag}, \mathrm{Cd}, \mathrm{Be}$ и $\mathrm{Sn}$. Несмотря на то, что растения быстро приспосабливаются к химическим стрессам, они все же мо-

Tаблица 1. Среднее содержание элементов в сухом веществе надзелной части Лабазника вязолистного (Filipéndula ulmária (L.) Maхіт.) на территории Ново-Урского хвостохранилища и коэффициенты концентрации относительно условного фона и кларка ноосферы, мг/кг

Table 1. Average content of elements in dry matter of the overground section of Meadowsweet (Filipendula ulmaria (L.) Maxim.) on the territory of the Novo-Urskoe tailing and coefficients of concentration relative to the conditional background and the clark of the noosphere, $\mathrm{mg} / \mathrm{kg}$

\begin{tabular}{|c|c|c|c|c|c|c|c|c|c|c|c|}
\hline 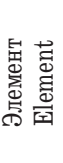 & $\begin{array}{c}\text { Среднее }\left(\mathrm{C}_{\mathrm{c}}\right), \\
\mathrm{мг} / \mathrm{kг} ;(\mathrm{n}=12) \\
\text { Average }\left(\mathrm{C}_{\mathrm{c}}\right), \\
\mathrm{mg} / \mathrm{kg} ;(\mathrm{n}=12)\end{array}$ & $\begin{array}{c}\text { Фон }(\Phi), \text { мг/кГ } \\
\text { Background } \\
(\Phi), \mathrm{mg} / \mathrm{kg}\end{array}$ & $\begin{array}{c}\text { Кларк ноосферы } \\
* *\left(\mathrm{~K}_{\mathrm{H}}\right), \mathrm{мг} / \text { кг } \\
\text { Clark of the no- } \\
\text { osphere } * *\left(\mathrm{~K}_{\mathrm{H}}\right) \text {, } \\
\mathrm{mg} / \mathrm{kg}\end{array}$ & 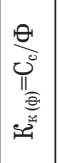 & 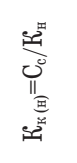 & 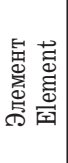 & $\begin{array}{c}\text { Среднее }\left(\mathrm{C}_{\mathrm{c}}\right) \text {, } \\
\text { мг/кг; }(\mathrm{n}=12) \\
\text { Average }\left(\mathrm{C}_{\mathrm{c}}\right) \\
\mathrm{mg} / \mathrm{kg} ;(\mathrm{n}=12)\end{array}$ & $\begin{array}{c}\text { Фон }(\Phi), \\
\text { мГ/кГ } \\
\text { Background } \\
(\Phi), \mathrm{mg} / \mathrm{kg}\end{array}$ & $\begin{array}{c}\text { Кларк ноосферы } * * \\
\left(\mathrm{~K}_{\mathrm{H}}\right), \mathrm{мг} / \text { кг } \\
\text { Clark of the no- } \\
\text { osphere } * *\left(\mathrm{~K}_{\mathrm{H}}\right) \\
\mathrm{mg} / \mathrm{kg}\end{array}$ & 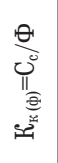 & 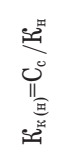 \\
\hline $\mathrm{Li}$ & $10,3 \pm 4,02$ & 5,67 & 19 & 1,8 & 0,5 & In* & $<0,002$ & 0,002 & 0,06 & - & - \\
\hline $\mathrm{Be}^{*}$ & $<0,15$ & 0,15 & 1 & - & - & Sn & $0,08 \pm 0,02$ & 0,03 & 4,9 & 3,2 & 0,02 \\
\hline B & $24,9 \pm 4,81$ & 18,7 & 50 & 1,3 & 0,5 & $\mathrm{Sb}$ & $0,11 \pm 0,03$ & 0,05 & 0,25 & 2,0 & 0,4 \\
\hline $\mathrm{Na}$ & $46,8 \pm 6,41$ & 21 & 19000 & 2,2 & 0,002 & Cs & $0,01 \pm 0,002$ & 0,007 & 5,9 & 1,5 & 0,002 \\
\hline $\mathrm{Mg}$ & $3590 \pm 496$ & 5548 & 9000 & 0,6 & 0,4 & $\mathrm{Ba}$ & $155 \pm 40,7$ & 9,48 & 36 & 16,4 & 4,3 \\
\hline $\mathrm{Al}$ & $119 \pm 21,6$ & 69 & 61000 & 1,7 & 0,002 & $\mathrm{La}$ & $0,06 \pm 0,01$ & 0,05 & 12 & 1,1 & 0,005 \\
\hline $\mathrm{Si}$ & $3129 \pm 973$ & 1448 & 165000 & 2,2 & 0,02 & $\mathrm{Ce}$ & $0,10 \pm 0,02$ & 0,11 & 32 & 0,9 & 0,003 \\
\hline $\mathrm{Nd}$ & $0,05 \pm 0,01$ & 0,05 & 16 & 0,9 & 0,003 & $\mathrm{~K}$ & $20145 \pm 1801$ & 14081 & 16000 & 1,4 & 1,3 \\
\hline $\operatorname{Pr}$ & $0,01 \pm 0,002$ & 0,01 & 3,8 & 0,9 & 0,003 & $\mathrm{P}$ & $2535 \pm 223$ & 2176 & 500 & 1,2 & 5,1 \\
\hline $\mathrm{Ca}$ & $6245 \pm 823$ & 7629 & 16000 & 0,8 & 0,4 & $\mathrm{Sm}$ & $0,01 \pm 0,004$ & 0,01 & 4,5 & 0,8 & 0,003 \\
\hline Sc & $0,11 \pm 0,03$ & 0,03 & 7 & 4,5 & 0,02 & $\mathrm{Eu}$ & $0,001 \pm 0,0004$ & 0,0004 & 0,64 & 3,3 & 0,002 \\
\hline $\mathrm{Ti}$ & $45,9 \pm 7,48$ & 35 & 4600 & 1,3 & 0,02 & $\mathrm{Gd}$ & $0,009 \pm 0,002$ & 0,007 & 4,9 & 1,4 & 0,002 \\
\hline $\mathrm{V}$ & $0,53 \pm 0,08$ & 0,6 & 70 & 0,9 & 0,008 & $\mathrm{~Tb}$ & $0,001 \pm 0,0002$ & 0,001 & 0,64 & 0,7 & 0,002 \\
\hline $\mathrm{Cr}$ & $2,79 \pm 0,13$ & 2,88 & 50 & 1,0 & 0,1 & Dy & $0,007 \pm 0,001$ & 0,003 & 3 & 2,4 & 0,002 \\
\hline $\mathrm{Mn}$ & $112 \pm 27,2$ & 40 & 440 & 2,8 & 0,3 & Ho & $0,001 \pm 0,0002$ & 0,0004 & 0,76 & 2,6 & 0,001 \\
\hline $\mathrm{Fe}$ & $177 \pm 26,4$ & 106 & 350 & 1,7 & 0,008 & Er & $0,003 \pm 0,0006$ & 0,001 & 1,7 & 3,3 & 0,005 \\
\hline Co & $0,37 \pm 0,04$ & 0,49 & 22 & 0,8 & 0,02 & $\mathrm{Tm}$ & $0,0003 \pm 0,00009$ & 0,0005 & - & 0,6 & - \\
\hline $\mathrm{Ni}$ & $2,01 \pm 0,65$ & 1,55 & 10 & 1,3 & 0,2 & $\mathrm{Yb}$ & $0,003 \pm 0,0006$ & 0,002 & 1,9 & 1,5 & 0,002 \\
\hline $\mathrm{Cu}$ & $8,89 \pm 0,90$ & 13,7 & 45 & 0,7 & 0,2 & $\mathrm{Lu}$ & $0,0006 \pm 0,00006$ & 0,0005 & 0,45 & 1,2 & 0,001 \\
\hline $\mathrm{Zn}$ & $112 \pm 29,7$ & 2 & 46 & 55,1 & 2,4 & $\mathrm{Hf}$ & $0,004 \pm 0,0007$ & 0,003 & 2,5 & 1,6 & 0,002 \\
\hline $\mathrm{Ga}$ & $0,06 \pm 0,007$ & 0,04 & 17 & 1,4 & 0,003 & $\mathrm{Ta}$ & $0,002 \pm 0,0004$ & 0,004 & 1,9 & 0,4 & 0,0009 \\
\hline $\mathrm{Ge}^{*}$ & $<0,15$ & 0,15 & 1,1 & - & - & W & $0,31 \pm 0,03$ & 0,05 & 1,3 & 5,9 & 0,2 \\
\hline As & $0,40 \pm 0,07$ & 0,33 & 3 & 1,2 & 0,1 & $\operatorname{Re}$ & $0,0009 \pm 0,0003$ & 0,0005 & 0,0005 & 1,7 & 1,9 \\
\hline $\mathrm{Se}$ & $7,15 \pm 2,13$ & 1 & 0,28 & 7,2 & 25,6 & $0 \mathrm{~s}^{*}$ & $<0,0005$ & 0,0005 & 0,03 & - & - \\
\hline $\mathrm{Rb}$ & $8,27 \pm 1,91$ & 5 & 96 & 1,7 & 0,1 & Ir* & $<0,001$ & 0,001 & 0,004 & - & - \\
\hline $\mathrm{Sr}$ & $16 \pm 2,13$ & 18 & 240 & 0,9 & 0,1 & $\mathrm{Pt}$ & $0,007 \pm 0,0003$ & 0,04 & 0,13 & 0,2 & 0,1 \\
\hline $\mathrm{Y}$ & $0,04 \pm 0,008$ & 0,03 & 20,5 & 1,4 & 0,002 & $\mathrm{Au}$ & $0,004 \pm 0,0003$ & 0,004 & 0,0007 & 1,1 & 6,3 \\
\hline $\mathrm{Zr}$ & $0,22 \pm 0,04$ & 0,15 & 12 & 1,4 & 0,02 & $\mathrm{Hg}$ & $0,08 \pm 0,02$ & 0,02 & 0,18 & 5,3 & 0,5 \\
\hline $\mathrm{Nb}$ & $0,02 \pm 0,003$ & 0,01 & 13 & 1,5 & 0,001 & $\mathrm{Tl}$ & $0,05 \pm 0,03$ & 0,006 & 0,79 & 8,7 & 0,1 \\
\hline Mo & $0,21 \pm 0,05$ & 0,97 & 1,1 & 0,2 & 0,2 & $\mathrm{~Pb}$ & $4,48 \pm 2,20$ & 0,34 & 12 & 13,3 & 0,4 \\
\hline $\mathrm{Ru}^{*}$ & $<0,05$ & 0,05 & 0,03 & - & - & $\mathrm{Bi}$ & $0,01 \pm 0,002$ & 0,005 & 0,005 & 2,5 & 1,9 \\
\hline $\mathrm{Rh} *$ & $<0,009$ & 0,009 & 0,006 & - & - & Th & $0,01 \pm 0,002$ & 0,008 & 7,6 & 1,4 & 0,001 \\
\hline $\mathrm{Cd}$ & $0,13 \pm 0,03$ & 0,04 & 0,16 & 3,3 & 0,8 & $\mathrm{U}$ & $0,004 \pm 0,0007$ & 0,004 & 1,9 & 1,1 & 0,002 \\
\hline $\mathrm{Ag}$ & $0,04 \pm 0,006$ & 0,007 & 0,05 & 6,0 & 0,9 & & & & & & \\
\hline
\end{tabular}

Примечание: $n$ - количество проб; * содержание элементов ниже предела определения; **по Н.Ф. Глазовскому [27].

Note: $n$ - number of samples; * the content of the elements is below the definition limit; **according to N.F. Glazovsky [27]. 
гут быть очень чувствительны к высоким концентрациям конкретного микроэлемента [26]. Лабазник вязолистный накапливает в больших концентрациях практически весь ряд перечисленных элементов.

По полученным аналитическим данным составлена таблица средних содержаний химических элементов надземной части лабазника вязолистного и рассчитаны коэффициенты концентрации относительно условно фоновой точки оз. Урское $\left(\mathrm{K}_{\kappa}\right.$ (ф)) и кларка ноосферы (Кк (н)). (табл. 1).

Исходя из данных табл. 1, средние содержания химических элементов в лабазнике вязолистном на территории хвостохранилища превышают фоновые значения для большинства элементов. Геохимический ряд, построенный относительно условного фона - оз. Урское, отражает избыточное накопление в 5 и более раз таких элементов, как $\mathrm{Zn}_{55,1}>\mathrm{Ba}_{16,4}>\mathrm{Pb}_{13,3}>\mathrm{Tl}_{8,7}>\mathrm{Se}_{7,2}>\mathrm{Ag}_{6,0}>\mathrm{W}_{5,9}>\mathrm{Hg}_{5,3}$.

Геохимическая специфика территории НовоУрского хвостохранилища отражается также в геохимическом ряде, построенном относительно кларка ноосферы. Представленные химические элементы превышают коэффициенты концентрации более чем в 2 раза: $\mathrm{Se}_{25,6}>\mathrm{Au}_{6,3}>\mathrm{P}_{5,1}>\mathrm{Ba}_{4,3}>\mathrm{Zn}_{2,4}$.

Полученные нами аналитические данные позволяют сделать вывод о том, что данный вид является хорошим индикатором изменений природной среды, происходящих в результате влияния НовоУрского хвостохранилища.

Так, на наш взгляд, накопление $\mathrm{Zn}, \mathrm{Ba}, \mathrm{Pb}, \mathrm{Ag}$, $\mathrm{Hg}, \mathrm{Au}$ напрямую зависит от их содержания в отвалах, поскольку, согласно литературным данным, именно такой спектр элементов характерен для отходов, складированных на изучаемой территории (табл. 2).

Накопление ртути в растениях, произрастающих на загрязненных участках, отмечается гораздо выше, чем в естественных условиях [29, 30].

Как показывают геохимические ряды, более целесообразным является применение местного условного фона, позволяющего получить более яркую картину по специфике влияния хвостов данного месторождения.

Повышенное содержания $\mathrm{Hg}$, с коэффициентом накопления более 5 , характерно для растений данной территории, потому что до недавнего времени в мировой практике широко применялся процесс извлечения благородных металлов при помощи жидкой ртути - амальгамации, что привело к ее накоплению в хвостохранилищах [29]. Изначально в складированных отходах Ново-Урского хвостохра- нилища выявлены высокие содержания $\mathrm{Hg}$ (в первичных 100 мкг/г, в окисленных 20-30 мкг/г). Данный фактор повлиял на распространение $\mathrm{Hg}$ в объектах окружающей среды не только вблизи хвостохранилища, но и на значительном удалении от него. Помимо фиксируемых нами накоплений, также выявлены высокие концентрации ртути в рыбе и грибах и установлено наличие элемента в питьевой воде поселка [31].

Повышенное содержание $\mathrm{Pb} \quad\left(\mathrm{K}_{\mathrm{K}}=13,3\right)$ и $\mathrm{Zn}\left(\mathrm{K}_{\mathrm{K}}=55,1\right)$ в составе лабазника вязолистного, отраженное в геохимических рядах на данной территории, связано с тем, что после переработки сульфид-содержащих руд в материалах отходов формируются кислые растворы с высоким содержанием этих и некоторых других элементов, которые широко распространяются и концентрируются путем перехода через корневую систему из питающих растворов в растениях [23].

Высокое содержание бария, с коэффициентом концентрации более 16 относительно фона и 4,3 относительно кларка ноосферы, в лабазнике вязолистном объясняется наличием минерала барита на месторождениях Урской группы [20, 32]. Формула барита $\mathrm{BaSO}_{4}$ с примесями $\mathrm{Sr}, \mathrm{Ca}, \mathrm{P}$ - эти элементы также имеют высокие концентрации по сравнению с фоновой точкой и кларком ноосферы.

Повышенная концентрация Se, относительно кларка ноосферы $\mathrm{K}_{\mathrm{r}}=25,6$ и относительно фона $\mathrm{K}_{\mathrm{K}}=7,2$, проявляется непосредственно благодаря образованию собственных минеральных форм тиманнита (селенида ртути - HgSe) [33] и преобладающему рудному материалу - пириту. Для сульфида железа нередкими примесями являются такие элементы, как $\mathrm{Se}, \mathrm{Co}, \mathrm{Ni}, \mathrm{As}, \mathrm{Cu}, \mathrm{Au}$. Также $\mathrm{Se}$ является примесью галенита - свинцовой руды, которая входит в состав рудных тел Ново-Урского месторождения [20, 32]. Его растворенные формы легко извлекаются растением из почв, что является известным фактором, согласно литературным источникам [26].

Таллий концентрируется в лабазнике вязолистном, собранном на территории Ново-Урского хвостохранилища, с коэффициентом более 8 относительно фоновых данных. Он входит в состав разнообразных минералов, главным образом сульфидов. Концентрация $\mathrm{Tl}$ в растении напрямую зависит от концентрации его в почве. Травянистые и древесные растения накапливают Tl больше, чем другие растительные виды. Согласно литературным данным, повышенное содержание $\mathrm{Tl}$ в тканях растения является токсичным $[1,26]$.

Таблища 2. Содержание элементов в отходах, образующих отваль Ново-Урского хвостохранилища

Table 2. Content of elements in the waste, forming the dumps of Novo-Urskoe tailing

\begin{tabular}{|c|c|c|c|c|c|c|c|c|c|c|c|c|c|c|c|}
\hline \multicolumn{2}{|r|}{ Элемент/Element } & $\mathrm{Cu}$ & $\mathrm{Mn}$ & $\mathrm{Zn}$ & $\mathrm{Au}$ & $\mathrm{Pb}$ & $\mathrm{Hg}$ & $\mathrm{Ag}$ & $\mathrm{Na}$ & $\mathrm{Al}$ & $\mathrm{Mg}$ & $\mathrm{K}$ & $\mathrm{Fe}$ & $\mathrm{Ca}$ & $\mathrm{Ba}$ \\
\hline & & & & $\mathrm{M \Gamma}$ & $\mathrm{i}(\mathrm{mg}$ & (kg) & & & \multicolumn{7}{|c|}{0} \\
\hline Отходы & Первичные руды/Primary ores & 122 & 25 & 174 & 0,6 & 1540 & 59 & 15 & 2 & 0,2 & 1,3 & 1,5 & 25 & 3 & 16 \\
\hline Tailings & Руды зон окисления/Ores oxidation zones & 100 & 45 & 134 & 0,47 & 190 & 65 & 11 & 0,5 & 2 & 0,1 & 0,5 & 7 & 0,3 & 4 \\
\hline
\end{tabular}

Примечание: по данныли И.Н. Мягкой и др. [28].

Note: according to I.N. Myagkoy and others [28]. 

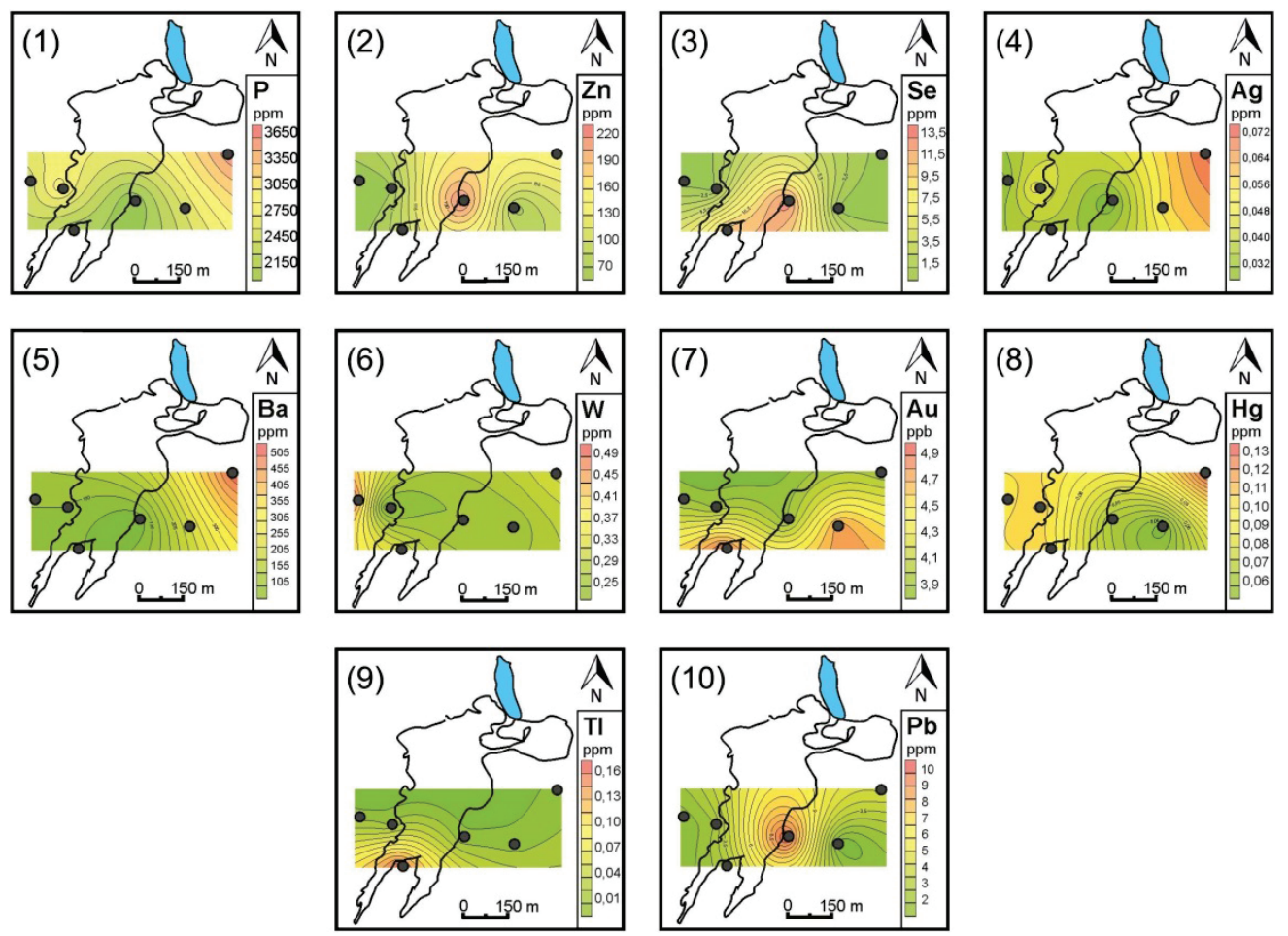

Puс.3. Картосхемы распределения химических элементов в надземной части Лабазника вязолистного (Filipéndula ulmária (L.) Maхіт.) на территории Ново-Урского хвостохранилища

Fig. 3. Map-scheme of chemical elements distribution in overground section of Meadowsweet (Filipendula ulmaria (L.) Maxim.) on the territory of Novo-Urskoe tailing
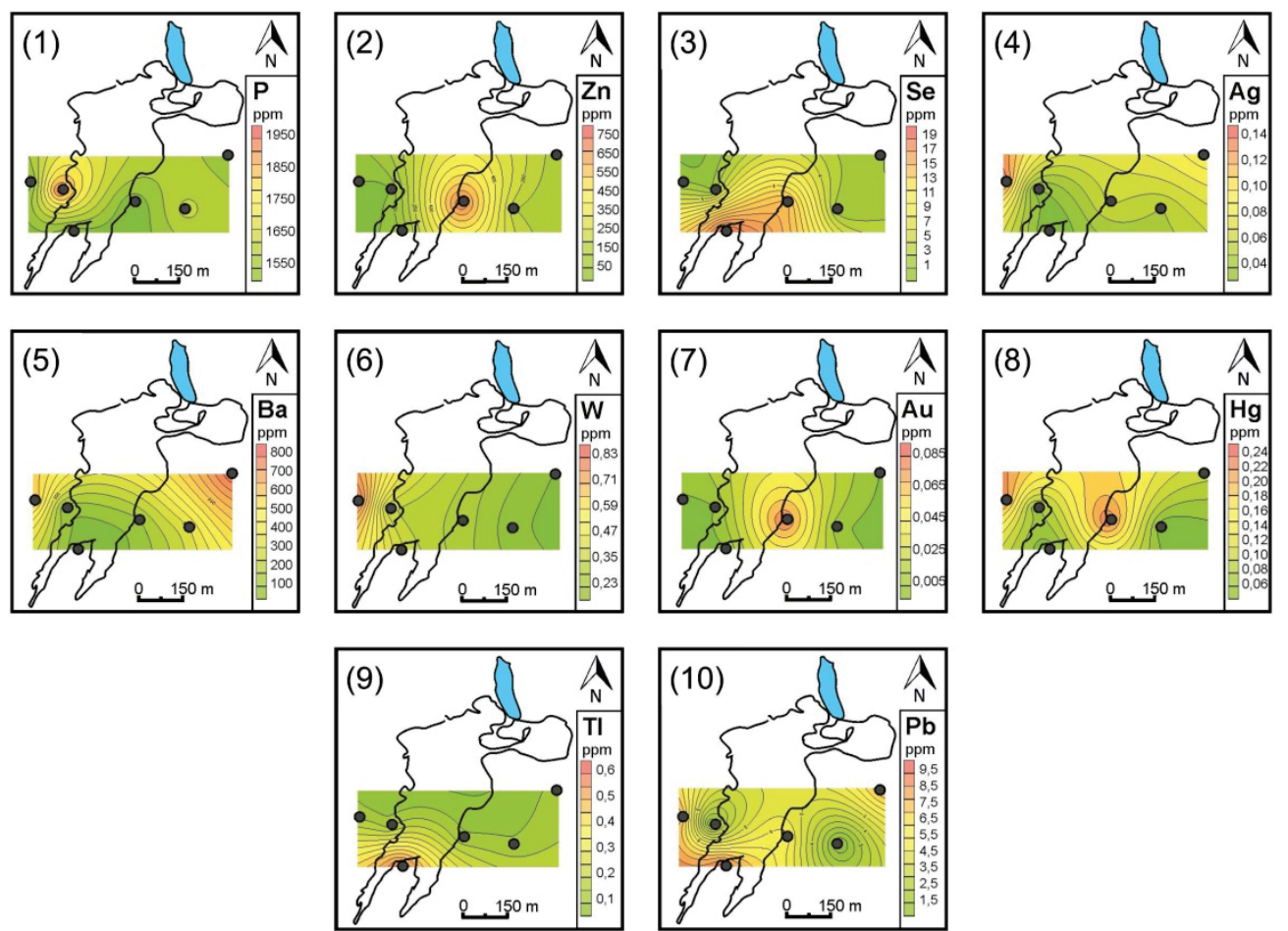

Puc. 4. Картосхемы распределения химических элементов в корневой части Лабазника вязолистного (Filipéndula ulmária (L.) Maхіт.) на территории Ново-Урского хвостохранилища

Fig. 4. Map-scheme of chemical elements distribution in root section of Meadowsweet (Filipendula ulmaria (L.) Maxim.) on the territory of Novo-Urskoe tailing 
Вольфрам при определенных условиях легкодоступен для растений. Поэтому, вероятно, его повышенные концентрации практически в 6 раз превышающие фон, характерны для растений, произрастающих на почвах, перекрывающих рудные тела. Токсичность $\mathrm{W}$ для растения оценивается как умеренная [26].

Нами также изучены особенности пространственного накопления в лабазнике вязолистном химических элементов, ярко выделяющихся в геохимических рядах относительно фоновой точки ( $\mathrm{Zn}, \mathrm{Ba}, \mathrm{Pb}, \mathrm{Tl}, \mathrm{Se}, \mathrm{Ag}, \mathrm{W}, \mathrm{Hg}$ ) и кларка ноосферы (Se, Au, P, Ba, Zn). Составлены картосхемы распределения элементов в надземной и корневой части растения вблизи хвостохранилища и на небольшом удалении от него (рис. 3,4$)$.

Анализ схем распределения химических элементов в лабазнике вязолистном свидетельствует о том, что в основном высокие концентрации элементов отмечаются в районе расположения отвала переработки окисленных руд и зоны потока рассеяния. Отвал окисленных руд проявляется по таким халькофильным элементам, как $\mathrm{Zn}, \mathrm{Se}, \mathrm{Pb}$, в надземной части растения и $\mathrm{Zn}, \mathrm{Se}, \mathrm{Au}$ и $\mathrm{Hg}$ в корнях.

Наибольшие концентрации $\mathrm{Se}, \mathrm{Tl}, \mathrm{Pb}$ в корневой части лабазника отмечаются в потоке рассеяния. Это может быть связано с тем, что дренажный ручей, протекающий по логу Ново-Урского хвостохранилища, способствует переходу многих химических элементов, которые распространяются по области рассеяния и легко поступают в корневую систему растения в растворенной форме. Высокие концентрации $\mathrm{Se}, \mathrm{Au}$ и $\mathrm{Tl}$ в надземной части растения также отмечаются в потоке рассеяния. Вблизи отвалов первичной руды зафиксировано повышенное накопление в корнях таких элементов, как $\mathrm{P}$, $\mathrm{Ag}$, и W, также отмечается повышенными концентрациями $\mathrm{W}$ и в надземной части растения.

Полученные данные позволяют предположить, что на содержание элементов в надземной части лабазника вязолистного большое влияние оказывает промплощадка. Такие элементы, как $\mathrm{P}, \mathrm{Ag}$, $\mathrm{Ba}, \mathrm{Hg}$, имеют высокое накопление в растении и входят в число основных компонентов первичных руд. В этом случае играет роль фактор пыления (при дроблении и сортировке отходов первичных руд). В корневой части Ва также проявляется в наибольшей концентрации вблизи промплощадки.

Нами изучены барьерные функции корневой системы лабазника вязолистного, произрастающего на территории Ново-Урского хвостохранилища. При сопоставлении содержания химических элементов в надземной и корневой частях растений было определено, что в корнях выявляются повышенные концентрации более чем в 80 \% случаях (табл. 3).

И.Г. Важенин [34] в качестве биоиндикатора загрязненности почвы предложил использовать коэффициент аккумуляции или коэффициент биологического поглощения - отношение концентра- ции элементов в корневой части растения относительно надземной. Показатель аккумуляции отображает адаптационные способности растений и обусловливается качествами растения и земли.

Нами рассчитаны коэффициенты аккумуляции лабазника вязолистного, согласно которым в корнях растений содержание таких элементов, как $\mathrm{Nb}$, Ce, Pr, La, Nd, Ta, Al, Lu, Th, Dy, Gd, Y, Yb, Er, Ho, $\mathrm{U}, \mathrm{Tb}, \mathrm{Eu}, \mathrm{Tm}$, в 10-20 раз выше, чем в надземных органах. Барьерная роль корневой системы выражена слабее в отношении $\mathrm{Fe}, \mathrm{Ga}, \mathrm{Na}, \mathrm{Cs}, \mathrm{Zr}, \mathrm{Sm}, \mathrm{Hf}$ : эти элементы имеют коэффициент аккумуляции 5-9, а у таких элементов, как $\mathrm{Hg}, \mathrm{Mn}, \mathrm{Ag}, \mathrm{Ti}, \mathrm{Co}$, $\mathrm{Zn}, \mathrm{Bi}, \mathrm{Ba}, \mathrm{Sr}, \mathrm{Tl}, \mathrm{As}, \mathrm{Sb}, \mathrm{Sc}, \mathrm{Cd}, \mathrm{V}, \mathrm{Au}$, коэффициент аккумуляции варьируется от 1,5 до 4 .

Таким образом, проведенные исследования аккумуляции 67 химических элементов в органах лабазника вязолистного показали, что примерно в $80 \%$ случаев химические элементы преимущественно аккумулируются в корневой части растения. И менее чем в $20 \%$ проявляется отсутствие барьерных механизмов защиты, что приводит к общему повышению содержания химических элементов в надземных органах растения.

\section{Заключение}

В результате проведенной работы нами установлено, что лабазник вязолистный (Filipéndula ulmária (L.) Maxim.) накапливает большой спектр химических элементов. В процессе проведения исследований на территории Ново-Урского хвостохранилища Кемеровской области выявлены повышенные концентрации таких элементов, как Zn, $\mathrm{Ba}, \mathrm{Pb}, \mathrm{Tl}, \mathrm{Se}, \mathrm{Ag}, \mathrm{W}, \mathrm{Hg}, \mathrm{Au}, \mathrm{P}$, по сравнению с фоновым показателем и относительно кларка ноосферы в 5 и более раз. Накопление этих элементов можно непосредственно связать с воздействием Ново-Урского хвостохранилища на объекты природной среды.

Проанализированы картосхемы распределения химических элементов в лабазнике вязолистном, из которых видно, что в основном высокие концентрации элементов фиксируются в районе расположения отвала переработки окисленных руд и зоны потока рассеяния. Также отмечается влияние промплощадки на концентрации химических элементов в надземной части за счет распространения элементов ветряными потоками.

Нами рассчитаны барьерные функции корневой системы лабазника вязолистного. Согласно коэффициенту аккумуляции, в корнях растений содержание таких элементов, как $\mathrm{Nb}, \mathrm{Ce}, \mathrm{Pr}, \mathrm{La}, \mathrm{Nd}$, Ta, Al, Lu, Th, Dy, Gd, Y, Yb, Er, Ho, U, Tb, Eu, Tm, в 10-20 раз выше, чем в надземных органах. В целом около 80 \% изученных нами химических элементов проявляются в более высоких концентрациях в корневой системе растения.

В целом проведенные исследования позволяют использовать данный вид в качестве биогеохимического индикатора по определенному спектру химических элементов для выявления специфики 
Таблица 3. Коэффициенты аккумуляции химических элементов в корневой части Лабазника вязолистного (Filipéndula ulmária (L.) Maxim.) по отношению к надземной части

Table 3. Coefficients of chemical elements accumulation in the root sections of Meadowsweet (Filipendula ulmaria (L.) Maxim.) in relation to the overground section

\begin{tabular}{|c|c|c|c|c|c|c|c|}
\hline $\begin{array}{l}\text { Элемент } \\
\text { Element }\end{array}$ & $\begin{array}{c}\text { Среднее }\left(\mathrm{C}_{\mathrm{c}}\right), \text { мг/кг; } \\
\text { Надземная часть } \\
\text { Average }\left(\mathrm{C}_{\mathrm{c}}\right), \mathrm{mg} / \mathrm{kg} ; \\
\text { Overground section }\end{array}$ & $\begin{array}{c}\text { Среднее }\left(\mathrm{C}_{\mathrm{c}}\right), \text { мг/кг; } \\
\text { Корневая часть } \\
\text { Average }\left(\mathrm{C}_{\mathrm{c}}\right), \mathrm{mg} / \mathrm{kg} ; \\
\text { Root sections }\end{array}$ & \begin{tabular}{|c|} 
Коэффициент \\
аккумуляции \\
Accumulation \\
coefficient
\end{tabular} & $\begin{array}{l}\text { Элемент } \\
\text { Element }\end{array}$ & $\begin{array}{l}\text { Среднее }\left(\mathrm{C}_{\mathrm{c}}\right), \text { мг/кг; } \\
\text { Надземная часть } \\
\text { Average }\left(\mathrm{C}_{\mathrm{c}}\right), \mathrm{mg} / \mathrm{kg} ; \\
\text { Overground section }\end{array}$ & $\begin{array}{l}\text { Среднее }\left(\mathrm{C}_{\mathrm{c}}\right), \mathrm{мг/кг;} \\
\text { Корневая часть } \\
\text { Average }\left(\mathrm{C}_{\mathrm{c}}\right), \mathrm{mg} / \mathrm{kg} \text {; } \\
\text { Root sections }\end{array}$ & $\begin{array}{c}\text { Коэффициент } \\
\text { аккумуляци } \\
\text { Accumulation } \\
\text { coefficient }\end{array}$ \\
\hline $\mathrm{Li}$ & $10,3 \pm 4,02$ & $1,12 \pm 0,52$ & 0,1 & In* & $<0,002$ & $<0,002$ & - \\
\hline $\mathrm{Be}^{*}$ & $<0,15$ & $<0,15$ & - & $\mathrm{Sn}$ & $0,08 \pm 0,02$ & $0,10 \pm 0,04$ & 1,3 \\
\hline $\mathrm{B}$ & $24,9 \pm 4,81$ & $27,0 \pm 4,84$ & 1,1 & $\mathrm{Sb}$ & $0,11 \pm 0,03$ & $0,27 \pm 0,11$ & 2,6 \\
\hline $\mathrm{Na}$ & $46,8 \pm 6,41$ & $305 \pm 103$ & 6,5 & Cs & $0,01 \pm 0,002$ & $0,08 \pm 0,05$ & 7,0 \\
\hline $\mathrm{Mg}$ & $3590 \pm 496$ & $2968 \pm 309$ & 0,8 & $\mathrm{Ba}$ & $155 \pm 40,7$ & $332 \pm 120$ & 2,1 \\
\hline $\mathrm{Al}$ & $119 \pm 21,6$ & $1326 \pm 752$ & 11,2 & $\mathrm{La}$ & $0,06 \pm 0,01$ & $0,60 \pm 0,32$ & 10,7 \\
\hline $\mathrm{Si}$ & $3129 \pm 973$ & $3953 \pm 2357$ & 1,3 & $\mathrm{Ce}$ & $0,10 \pm 0,02$ & $1,03 \pm 0,60$ & 10,5 \\
\hline $\mathrm{Nd}$ & $0,05 \pm 0,01$ & $0,49 \pm 0,30$ & 10,8 & $\mathrm{~K}$ & $20145 \pm 1801$ & $11539 \pm 674$ & 0,6 \\
\hline $\operatorname{Pr}$ & $0,01 \pm 0,002$ & $0,12 \pm 0,07$ & 10,5 & $P$ & $2535 \pm 223$ & $1620 \pm 75,8$ & 0,6 \\
\hline $\mathrm{Ca}$ & $6245 \pm 823$ & $6532 \pm 511$ & 1,0 & $\mathrm{Sm}$ & $0,01 \pm 0,004$ & $0,10 \pm 0,06$ & 8,8 \\
\hline Sc & $0,11 \pm 0,03$ & $0,30 \pm 0,09$ & 2,7 & $\mathrm{Eu}$ & $0,001 \pm 0,0004$ & $0,02 \pm 0,02$ & 19,9 \\
\hline $\mathrm{Ti}$ & $45,9 \pm 7,48$ & $85,6 \pm 48,0$ & 1,9 & $\mathrm{Gd}$ & $0,009 \pm 0,002$ & $0,12 \pm 0,07$ & 12,9 \\
\hline $\mathrm{V}$ & $0,53 \pm 0,08$ & $1,91 \pm 1,08$ & 3,6 & $\mathrm{~Tb}$ & $0,001 \pm 0,0002$ & $0,02 \pm 0,01$ & 15,5 \\
\hline $\mathrm{Cr}$ & $2,79 \pm 0,13$ & $3,58 \pm 0,78$ & 1,3 & Dy & $0,007 \pm 0,001$ & $0,08 \pm 0,05$ & 12,4 \\
\hline $\mathrm{Mn}$ & $112 \pm 27,2$ & $206 \pm 75,1$ & 1,8 & Ho & $0,001 \pm 0,0002$ & $0,02 \pm 0,01$ & 15,3 \\
\hline $\mathrm{Fe}$ & $177 \pm 26,4$ & $890 \pm 450$ & 5,0 & $\mathrm{Er}$ & $0,003 \pm 0,0006$ & $0,05 \pm 0,03$ & 15,0 \\
\hline Co & $0,37 \pm 0,04$ & $0,72 \pm 0,20$ & 1,9 & $\mathrm{Tm}$ & $0,0003 \pm 0,00009$ & $0,01 \pm 0,004$ & 20,2 \\
\hline $\mathrm{Ni}$ & $2,01 \pm 0,65$ & $2,40 \pm 0,95$ & 1,2 & $\mathrm{Yb}$ & $0,003 \pm 0,0006$ & $0,04 \pm 0,03$ & 14,6 \\
\hline $\mathrm{Cu}$ & $8,89 \pm 0,90$ & $10,7 \pm 1,23$ & 1,2 & $\mathrm{Lu}$ & $0,0006 \pm 0,00006$ & $0,01 \pm 0,004$ & 11,4 \\
\hline $\mathrm{Zn}$ & $112 \pm 29,7$ & $209 \pm 103$ & 1,9 & $\mathrm{Hf}$ & $0,004 \pm 0,0007$ & $0,04 \pm 0,02$ & 9,3 \\
\hline $\mathrm{Ga}$ & $0,06 \pm 0,007$ & $0,31 \pm 0,17$ & 5,3 & $\mathrm{Ta}$ & $0,002 \pm 0,0004$ & $0,02 \pm 0,01$ & 10,9 \\
\hline $\mathrm{Ge}^{*}$ & $<0,15$ & $<0,15$ & - & $\mathrm{W}$ & $0,31 \pm 0,03$ & $0,39 \pm 0,10$ & 1,2 \\
\hline As & $0,40 \pm 0,07$ & $1,05 \pm 0,30$ & 2,6 & $\operatorname{Re}$ & $0,0009 \pm 0,0003$ & $<0,0009$ & 0,6 \\
\hline $\mathrm{Se}$ & $7,15 \pm 2,13$ & $5,76 \pm 3,10$ & 0,8 & $0 \mathrm{~s}^{*}$ & $<0,0005$ & $<0,0005$ & - \\
\hline $\mathrm{Rb}$ & $8,27 \pm 1,91$ & $5,42 \pm 1,51$ & 0,7 & Ir* & $<0,001$ & $<0,001$ & - \\
\hline $\mathrm{Sr}$ & $16,02 \pm 2,13$ & $34,9 \pm 4,30$ & 2,2 & $\mathrm{Pt}$ & $0,007 \pm 0,0003$ & $0,01 \pm 0,001$ & 1,1 \\
\hline $\mathrm{Y}$ & $0,04 \pm 0,008$ & $0,54 \pm 0,28$ & 13,8 & $\mathrm{Au}$ & $0,004 \pm 0,0003$ & $0,02 \pm 0,01$ & 4,3 \\
\hline $\mathrm{Zr}$ & $0,22 \pm 0,04$ & $1,78 \pm 1,16$ & 8,2 & $\mathrm{Hg}$ & $0,08 \pm 0,02$ & $0,13 \pm 0,04$ & 1,5 \\
\hline $\mathrm{Nb}$ & $0,02 \pm 0,003$ & $0,20 \pm 0,13$ & 10,5 & $\mathrm{Tl}$ & $0,05 \pm 0,03$ & $0,12 \pm 0,09$ & 2,5 \\
\hline Mo & $0,21 \pm 0,05$ & $0,19 \pm 0,03$ & 0,9 & $\mathrm{~Pb}$ & $4,48 \pm 2,20$ & $6,00 \pm 1,44$ & 1,3 \\
\hline $\mathrm{Ru}^{*}$ & $<0,05$ & $<0,05$ & - & $\mathrm{Bi}$ & $0,01 \pm 0,002$ & $0,02 \pm 0,01$ & 2,0 \\
\hline $\mathrm{Rh}^{*}$ & $<0,009$ & $<0,009$ & - & Th & $0,01 \pm 0,002$ & $0,13 \pm 0,09$ & 11,9 \\
\hline $\mathrm{Cd}$ & $0,13 \pm 0,03$ & $0,37 \pm 0,11$ & 2,8 & $\mathrm{U}$ & $0,004 \pm 0,0007$ & $0,06 \pm 0,03$ & 15,4 \\
\hline $\mathrm{Ag}$ & $0,04 \pm 0,006$ & $0,08 \pm 0,02$ & 1,8 & & & & \\
\hline
\end{tabular}

Примечание: $n$ - количество проб; * содержание элементов ниже предела определения.

Note: $n$ - number of samples; * the content of the elements is below the definition limit.

техногенного воздействия в зонах влияния объектов горнорудного производства с золото-полиметаллической специализацией.

Авторы выражают благодарность доктору геолого-минералогических наук, профессору Л.П. Рихванову за орга

\section{СПИСОК ЛИТЕРАТУРЫ}

1. Ильин В.Б. Тяжелые металлы и неметаллы в системе почва-растение. - Новосибирск: Изд-во СО РАН, 2012. - 220 с.

2. Геохимические особенности элементного состава листьев тополя урбанизированных территорий / Д.В. Юсупов, Л.П. Рихванов, Н.В. Барановская, А.Р. Ялалтдинова // Известия Томского политехнического университета. Инжиниринг георесурсов. - 2016. - Т. 327. - № 6. - С. 25-36.

3. Assessment of mercury content in poplar leaves of Novokuznetsk agglomeration / E.E. Lyapina, D.V. Yusupov, E.M. Tursunalieva, V.V. Osipova // IOP Conference Series: Earth and Environmental Science. - 2016. - № 48 (1). - P. 012022.

4. Радомская В.И., Радомский С.М., Юсупов Д.В., Моисеенко В.Г. Биоаккумуляция благородных металлов растениями // Доклады Академии наук. - 2003. - Т. 388. - № 1. - С. 93-96. низацию и помощь в проведении экспедиционных работ, $a$ также за обсуждение результатов исследования.

Работа выполнена при поддержке гранта Российского научного фонда № 15-17-10011.

5. Baker A.J.M. Accumulators and excluders strategies in the response of plants to heavy metals // J. Plant Nutr. - 1981. - V. 3. № $1 / 4 .-$ P. 643-654.

6. Heavy metal stress in plants: from biomolecules to ecosystems // Ed. by M.N.V. Prasad. - Luxembourg: Springer Science \& Business Media, 2013. $-461 \mathrm{p}$.

7. Chibuike G.U., Obiora S.C. Heavy metal polluted soils: effect on plants and bioremediation methods //Applied and Environmental Soil Science. - 2014. - V. 2014. - P. 1-12.

8. Rajewska I., Talarek M., Bajguz A. Brassinosteroids and response of plants to heavy metals action / Frontiers in plant science. 2016. - V. 7. - P. 629.

9. Титов А.Ф., Казнина Н.М., Таланова В.В. Тяжелые металлы и растения. - Петрозаводск: Карельский научный центр РАН, 2014. -197 c. 
10. Колесникова (Горбатюк) Е.А., Барановская Н.В., Черненькая Е.В. Региональные особенности элементного состава надземной части Filipendula ulmaria (Rosaceae) (юг Сибири) // Биогеохимия техногенеза и современные проблемы геохимической экологии: Труды IX Международной биогеохимической школы. - Барнаул, 2015. - Т. II. - С. 139-142.

11. Pukalskiene M., Venskutonis P.R., Pukalskas A. Phytochemical characterization of Filipendula ulmaria by UPLC/Q-TOF-MS and evaluation of antioxidant activity // Records of Natural Products. - 2015. - V. 9. - № 3. - P. 451-455.

12. Geochemical features of the elemental composition of meadowsweet (Filipendula ulmaria (L). Maxim) in Kemerovo Oblast / V.A. Zhdanov, I.S. Sobolev, N.V. Baranovskaya, E.A. Kolesnikova (Gorbatuyk), E.V. Chernenkaya, A.R. Yalaltdinova. // IOP Conference Series: Earth and Environmental Science. - 2016. V. 43. - № 1. - P. 012048.

13. Betula Pendula R. Leaves for the assessment of environmental pollution by metals around tailings from a gold deposit (Western Siberia, Russia) / D.V. Yusupov, T.S. Bolshunova, A.M. Mezhibor, L.P. Rikhvanov, N.V. Baranovskaya // International Multidisciplinary Scientific GeoConference Surveying Geology and Mining Ecology Management, SGEM. - 2017. - V. 17 (41). P. $665-672$.

14. Biogeochemical features of epiphytyc lichens from the area of the tailing of a gold-polymetallic deposit (Kemerovo region, Russia) comparative to a reference area / T.S. Bolshunova, L.P. Rikhvanov, A.M. Mezhibor, N.V. Baranovskaya, D.V. Yusupov // International Multidisciplinary Scientific GeoConference Surveying Geology and Mining Ecology Management, SGEM. - 2017. V. 17 (51). - P. 165-172.

15. Yusupov D.V., Karpenko Yu.A. REE, Uranium (U) and Thorium (Th) contents in Betula pendula leaf growing around Komsomolsk gold concentration plant tailing (Kemerovo region, Western Siberia, Russia) // IOP Conference Series: Earth and Environmental Science. - 2016. - V. 43 (1) - P. 012053.

16. Атлас лекарственных растений России / под ред. В.А. Быкова. М.: ВИЛАР, 2006. - 376 c.

17. In vitro and in vivo assessment of meadowsweet (Filipendula ulmaria) as anti-inflammatory agent / J. Katanic, T. Boroja, V. Mihailović, S. Nikles, S.P. Pan, G. Rosić, R. Bauer // Journal of ethnopharmacology. - 2016. - V. 193. - P. 627-636.

18. Юркевич Н.В., Бортникова С.Б., Саева О.П. Направления подземного и поверхностного стоков с хвостохранилищ горнорудного производства по данным геофизических и геохимических исследований // Интерэкспо Гео-Сибирь. - 2015. - Т. 2. № 2. - С. 305-310.

19. Формирование и источники питания россыпей Северо-Восточного Салаира / Г.В. Нестеренко, С.Р. Осинцев, Д.И. Портников и др. // Условия образования, принципы прогноза и поисков золоторудных месторождений. Труды ИГиГ. Новосибирск: Наука, 1983. - Вып. 533. - С. 166-194.

20. Черепнин В.К. К вопросу о составе и генезисе руд Урских месторождений Салаира // Известия Томск политехнического института. - 1958. - Т. 90. - С. 56-70.

21. Вертикальное и латеральное распространение высокоминерализованных растворов кислого дренажа по данным электротомографии и гидрогеохимии (Урской отвал, Салаир) /
В.В. Оленченко, Д.О. Кучер, С.Б. Бортникова, О.Л. Гаськова, А.В. Еделев, М.П. Гора // Геология и геофизика. - 2016. T. 57. - № 4. - C. 782-795.

22. Формы миграции химических элементов из сульфидных отходов горнодобывающей промышленности / Н.В. Юркевич, О.Л. Гаськова, О.П. Саева, Т.В. Корнеева // Интерэкспо ГеоСибирь. - 2014. - Т. 2. - № 3. - С. 163-169.

23. Миграция тяжелых металлов (Cu, $\mathrm{Pb}, \mathrm{Zn}, \mathrm{Fe}, \mathrm{Cd})$ в ореоле рассеяния Урского хвостохранилища (Кемеровская область) / И.Н. Щербакова, М.А. Густайтис, Е.В. Лазарева, А.А. Богуш // Химия в интересах устойчивого развития. - 2010. - Т. 18. C. $621-633$.

24. Effect of drying methods on the phenolic constituents of meadowsweet (Filipendula ulmaria) and willow (Salix alba) / N. Harbourne, E. Marete, J.C. Jacquier, D. 0'Riordan / LWT-Food Science and Technology. - 2009. - V. 42. - № 9. - P. 1468-1473.

25. Использование метода масс-спектрометрии с индуктивно-связанной плазмой в элементном анализе объъектов окружающей среды / В.К. Карандашев, А.Н. Туранов, Т.А. Орлова, А.Е. Лежнев, С.В. Носенко, Н.И. Золотарева, И.Р. Москвина // Заводская лаборатория. Диагностика материалов. - 2007. T. 73. - № 1. - C. 12-22.

26. Kabata-Pendias A. Trace Elements in Soils and Plants. $4^{\text {th }}$ ed. USA, BocaRaton: CRC Press, 2011. - 505 p.

27. Глазовский Н.Ф. Техногенные потоки веществ в биосфере // Добыча полезных ископаемых и геохимия природных экосистем. - М.: Наука, 1982. - С. 7-28.

28. Перераспределение $\mathrm{Au}$ и $\mathrm{Ag}$ между отходами обогащения руд Ново-Урского месторождения и торфом в системе хвостохранилища / И.Н. Мягкая, Е.В. Лазарева, М.А. Густайтис, Б.Л. Щербов, С.М. Жмодик // Геология и минерально-сырьевые ресурсы Сибири. - 2014. - № 3. - С. 477-483.

29. Росляков Н.А., Кириллова 0.В. Ртутное загрязнение окружающей среды при добыче золота в России // Химия в интересах устойчивого развития. - 1995. - Т. 3. - № 1-2. - С. 43-55.

30. Межибор А.М., Рихванов Л.П. Биогеохимическая характеристика мхов Polytrichum commune на территории Урского хвостохранилища в Кемеровской области // Безопасность в техносфере. - 2016. - T. 5. - № 1. - С. 3-11.

31. Загрязнение ртутью окружающей среды после эксплуатации Ново-Урского золоторудного месторождения (Кемеровская область) / М.А. Густайтис, И.Н. Мягкая, Б.Л. Щербов, Е.В. Лазарева // Известия Иркутского государственного университета. Серия: Науки о Земле. - 2016. - Т. 18. - С. 14-24.

32. Болгов Г.П. Сульфиды Салаира. Урская группа полиметаллических месторождений // Известия Томского индустриального института. - 1937. - Т. 58. - С. 45-96.

33. Мягкая И.Н. Минералого-геохимические особенности концентрирования золота органическим веществом в системе сульфидные отвалы - торф (на примере Урского хвостохранилища, Кемеровская область, Россия): автореф. дис. канд.геолого-минералогических наук. - Новосибирск, 2013. - 16 с.

34. Важенин И.Г. Корни растений как биоиндикатор уровня загрязненности почвы токсическими элементами // Агрохимия. - 1984. - № 2. - С. 73-77.

Поступила 18.10.2018 г.

\section{Информация об авторах}

Горбатюк $\boldsymbol{E} . \boldsymbol{A}$., аспирант кафедры геоэкологии и геохимии Инженерной школы природных ресурсов Национального исследовательского Томского политехнического университета.

Барановская H.B., доктор биологических наук, профессор кафедры геоэкологии и геохимии Инженерной школы природных ресурсов Национального исследовательского Томского политехнического университета.

жәанов В.A., студент кафедры геоэкологии и геохимии Инженерной школы природных ресурсов Национального исследовательского Томского политехнического университета. 
UDC 581.1:574:550.4 (571.17)

\title{
GEOCHEMICAL FEATURES OF THE FILIPENDULA ULMARIA (L.) MAXIM (ROSACEAE) ELEMENTAL COMPOSITION IN THE TERRITORY OF NOVO-URSKOE TAILING, KEMEROVO REGION
}

\author{
Ekaterina A. Gorbatyuk',
}

kolesnikovaea@tpu.ru

\author{
Natalia V. Baranovskaya', \\ nata@tpu.ru \\ Vadim A. Zhdanov', \\ hyfrvadim@gmail.com \\ ${ }^{1}$ National Research Tomsk Polytechnic University, \\ 30, Lenin avenue, Tomsk, 634050, Russia.
}

\begin{abstract}
The relevance of the research is caused by the need for comprehensive information on the impact of biogeochemical background radi$\mathrm{cal}$ changes in the areas of mining enterprises tailings distribution. The research is aimed to predict routes of toxic components migration. The aim of the research is to identify the changes in elemental composition of the root and overground sections of Meadowsweet (Filipendula ulmaria (L.) Maxim.) and to determine indicators of the Novo-Urskoe deposit tailing's technogenic impact. The objective of the research is to determine coefficients of chemical elements concentrations relative to the background values as well as coefficients of the chemical elements accumulation in the root section of the meadowsweet in reference to overground one. Another objective of the research is to study the features of the spatial distribution of chemical elements in overground and root sections of meadowsweet in the tailing site. Methods. Sampling was arranged on the flanks of Novo-Urskoe tailing. The elemental composition of meadowsweet was carried out by the certified methods using the technique of mass spectrometry with inductively coupled plasma (ICP-MS) in the laboratory of the "Plasma» analytical center (Tomsk city). The analytical data processing was performed through Statistica 6.0 and Excel programs. Maps of elements distribution in overground and root sections were made using the programs: Surfer (11), CorelDRAW (16).

Results. Accumulation of 67 chemical elements in meadowsweet from Novo-Urskoe tailing in Kemerovo region was studied. Coefficients of element concentrations relative to the background and a clark of the noosphere were calculated. The authors have compiled the geochemical ranks, showing accumulation of elements such as $\mathrm{Zn}, \mathrm{Ba}, \mathrm{Pb}, \mathrm{Tl}, \mathrm{Se}, \mathrm{Ag}, \mathrm{W}, \mathrm{Hg}, \mathrm{Au}, \mathrm{P}$, which exceed background values in 5 and more times. Maps of spatial distribution of chemical elements in meadowsweet showed that the highest concentrations of elements are in the area of the dump of oxidized ore processing and in the area of dispersion flux. The coefficients of accumulation of chemical elements in the root section of meadowsweet in reference to overground section were calculated. The authors identified the increased concentrations of chemical elements in the roots approximately in $80 \%$ of cases.
\end{abstract}

\section{Key words:}

Meadowsweet (Filipendula ulmaria (L.) Maxim.), chemical elements, Novo-Urskoe tailing, coefficients of concentrations, coefficients of accumulation.

The authors are grateful to L.P. Rikhvanov, Dr. Sc., professor, for organizing and assisting in carrying out expedition works and for discussion of the results of the research.

The research was supported by the grant of the Russian Science Fund no. 15-17-10011.

\section{REFERENCES}

1. Ilin V.B. Tyazhelye metally i nemetally $v$ sisteme pochva-rastenie [Heavy metals and non-metals in the soil-plant system]. Novosibirsk, SO RAN Publ., 2012. 220 p.

2. Yusupov D.V., Rikhvanov L.P., Baranovskaya N.V., Yalaltdinova A.R. Geochemical features of poplar leaf elemental composition in urban areas. Bulletin of the Tomsk Polytechnic University, Geo Assets Engineering, 2016, vol. 327, no. 6, pp. 25 ?36.

3. Lyapina E.E., Yusupov D.V., Tursunalieva E.M., Osipova V.V. Assessment of mercury content in poplar leaves of Novokuznetsk agglomeration. IOP Conference Series: Earth and Environmental Science, 2016, no. 48 (1), pp. 012022.

4. Radomskaya V.I., Radomskij S.M., Yusupov D.V., Moiseenko V.G. Bioaccumulation of noble metals in plants. Doklady Akademii Nauk, 2003, vol. 388, no. 1, pp. 34-37.

5. Baker A.J.M. Accumulators and excluders strategies in the response of plants to heavy metals. J. Plant Nutr., 1981, vol. 3, no. $1 / 4$, pp. $643-654$.

6. Heavy metal stress in plants: from biomolecules to ecosystems. Ed. by M.N.V. Prasad. Luxembourg, Springer Science \& Business Media, 2013. $461 \mathrm{p}$.
7. Chibuike G.U., Obiora S.C. Heavy metal polluted soils: effect on plants and bioremediation methods. Applied and Environmental Soil Science, 2014, vol. 2014, pp. 1 ?12.

8. Rajewska I., Talarek M., Bajguz A. Brassinosteroids and response of plants to heavy metals action. Frontiers in plant science, 2016, vol. 7, pp. 629 .

9. Titov A.F., Kaznina N.M., Talanova V.V. Tyazhelye metally i rasteniya [Heavy metals and plants]. Petrozavodsk, Karelsky nauchny centr RAN Publ., 2014. $197 \mathrm{p}$.

10. Kolesnikova (Gorbatyuk) E.A., Baranovskaya N.V., Chernenkaya E.V. Regionalnye osobennosti elementnogo sostava nadzemnoy chasti Filipendula ulmaria (Rosaceae) (yug Sibiri) [Regional features of the elemental composition of the aerial part of Filipendula ulmaria (Rosaceae) (southern Siberia)]. Biogeokhimiya tekhnigeneza $i$ souremennye problemy geokhimicheskoy ekologii. Trudy IX Mezhdunarodnoy biogeokhimicheskoy shkoly [Proc. of the IX International Biogeochemical School: The Biogeochemistry of Technogenesis and Current Problems of Geochemical Ecology]. Barnaul, 2015. Vol. II, pp. 139-142.

11. Pukalskiene M., Venskutonis P. R., Pukalskas A. Phytochemical characterization of Filipendula ulmaria by UPLC/Q-TOF-MS and evaluation of antioxidant activity. Records of Natural Products, 2015, vol. 9, no. 3, pp. 451-455. 
12. Zhdanov V.A., Sobolev I.S., Baranovskaya N.V., Kolesnikova (Gorbatuyk) E.A., Chernenkaya E.V., Yalaltdinova A.R. Geochemical features of the elemental composition of meadowsweet (Filipendula ulmaria (L). Maxim) in Kemerovo Oblast. IOP Conference Series: Earth and Environmental Science, 2016, vol. 43, no. 1, pp. 012048.

13. Yusupov D.V., Bolshunova T.S., Mezhibor A.M., Rikhvanov L.P., Baranovskaya N.V. Betula Pendula R. Leaves for the assessment of environmental pollution by metals around tailings from a gold deposit (Western Siberia, Russia). International Multidisciplina ry Scientific GeoConference Surveying Geology and Mining Ecology Management, SGEM, 2017, vol. 17 (41), pp. 665-672.

14. Bolshunova T.S., Rikhvanov L.P., Mezhibor A.M., Baranovskaya N.V., Yusupov D.V. Biogeochemical features of epiphytyc lichens from the area of the tailing of a gold-polymetallic deposit (Kemerovo region, Russia) comparative to a reference area. International Multidiscipli nary Scientific GeoConference Surveying Geology and Mining Ecology Management, SGEM, 2017, vol. 17 (51), pp. 165-172.

15. Yusupov D.V., Karpenko Yu.A. REE, Uranium (U) and Thorium (Th) contents in Betula pendula leaf growing around Komsomolsk gold concentration plant tailing (Kemerovo region, Western Siberia, Russia). IOP Conference Series: Earth and Environmental Science, 2016, vol. 43 (1), pp. 012053.

16. Bykov V.A. Atlas lekarstvennykh rasteniy Rossii [Atlas of medicinal plants of Russia]. Moscow, VILAR Publ., 2006. 376 p.

17. Katanić J., Boroja T., Mihailović V., Nikles S., Pan S. P., Rosic G, Bauer R. In vitro and in vivo assessment of meadowsweet (Filipendula ulmaria) as anti-inflammatory agent. Journal of ethnopharmacology, 2016, vol. 193, pp. 627-636.

18. Yurkevich N.V., Bortnikova S.B., Saeva O.P. Napravleniya podzemnogo i poverkhnostnogo stokov s khvostokhranilishch gornorudnogo proizvodstva po dannym geofizicheskikh i geokhimicheskikh issledovaniy [Directions of underground and surface runoff from tailings of mining production according to geophysical and geochemical studies]. Interexpo Geo-Siberia, 2015, vol. 2, no. 2, pp. 305-310.

19. Nesterenko G.V., Osintsev S.R., Portnikov D.I. Formirovanie i istochniki pitaniya rossypey Severo-Vostochnogo Salaira [Formation and power sources of placers of the North-Eastern Salair]. Usloviya obrazovaniya, pribtsipy prognoza i poiskov zolotorudnykh mestorozhdeny. Trudy IGiG [Formation conditions, principles of forecasting and prospecting for gold deposits. IGG Proc.]. Vyp. 533, Novosibirsk, Nauka Publ., 1983. pp. 166-194.

20. Cherepnin V.K. K voprosu o sostave i genezise rud Urskikh mestorozhdeniy Salaira [0n the issue of composition and genesis of the ores of the Urskoye Salair deposits]. Bulletin of Tomsk Polytechnic Institute, 1958, vol. 90, pp. 56-70.

21. Olenchenko V.V., Kucher D.O., Bortnikova S.B., Gaskova O.L., Edelev A.V., Gora M.P. Vertikalnoe i lateralnoe rasprostranenie vysokomineralizovannykh rastvorov kislogo drenazha po dannym elektrotomografii i gidrogeokhimii (Urskoy otval, Salair) [Vertical and lateral distribution of highly mineralized solutions of acidic drainage according to electro-tomography and hydrogeochemistry (Urskoy dump, Salair)]. Geology and Geophysics, 2016, vol. 57, no. 4, pp. 782-795.

22. Yurkevich N.V., Gaskova O.L., Saeva 0.P., Korneeva T.V. Formy migratsii khimicheskikh elementov iz sulfidnykh otkhodov gornodobyvayushchey promyshlennosti [Forms of migration of chemical elements from sulphide mining waste]. Interexpo Geo-Siberia, 2014, vol. 2, no. 3, pp. 163-169.

23. Shcherbakova I.N., Gustaytis M.A., Lazareva E.V., Bogush A.A. Migratsiya tyazhelykh metallov $(\mathrm{Cu}, \mathrm{Pb}, \mathrm{Zn}, \mathrm{Fe}, \mathrm{Cd})$ v oreole rasseyaniya Urskogo khvostokhranilishcha (Kemerovskaya oblast)
[Migration of heavy metals ( $\mathrm{Cu}, \mathrm{Pb}, \mathrm{Zn}, \mathrm{Fe}, \mathrm{Cd})$ in the aureole of Ursk tailing (Kemerovo region)]. Chemistry for sustainable Development, 2010, vol. 18, pp. 621-633.

24. Harbourne N., Marete E., Jacquier J.C., O'Riordan D. Effect of drying methods on the phenolic constituents of meadowsweet (Filipendula ulmaria) and willow (Salix alba). LWT-Food Science and Technology, 2009, vol. 42, no. 9, pp. 1468-1473.

25. Karandashev V.K., Turanov A.N., Orlova T.A., Lezhnev A.E., Nosenko S.V., Zolotareva N.I., Moskvina I.R. Ispolzovanie metoda mass-spektrometrii s induktivno-svyazannoy plazmoy v elementnom analize obektov okruzhayushchey sredy [Using inductively coupled plasma mass spectrometry in elemental analysis of environmental objects]. Factory laboratory. Diagnostics of materials, 2007, vol. 73, no. 1, pp. 12-22.

26. Kabata-Pendias A. Trace Elements in Soils and Plants. $4^{\text {th }}$ ed. BocaRaton, USA, CRC Press, 2011. 505 p.

27. Glazovskiy N.F. Tekhnogennye potoki veshchestv v biosfere [Technogenic flows of substances in the biosphere]. Dobycha poleznykh iskopaemykh i geokhimiya prirodnykh ekosistem [Mining and geochemistry of natural ecosystems]. Moscow, Nauka Publ., 1982. pp. 7-28.

28. Myagkaya I.N., Lazareva E.V., Gustaytis M.A., Shcherbov B.L., Zhmodik S.M. Pereraspredelenie Au i Ag mezhdu otkhodami obogashcheniya rud Novo-Urskogo mestorozhdeniya i torfom v sisteme khvostokhranilishcha [Au and $\mathrm{Ag}$ redistribution between the ore dressing waste of the Novo-Ursky deposit and peat in the tailings system]. Geology and mineral resources of Siberia, 2014, no. 3 , pp. $477-483$.

29. Roslyakov N.A., Kirillova 0.V. Rtutnoe zagryaznenie okruzhayushchey sredy pri dobyche zolota v Rossii [Mercury Pollution in Gold Mining in Russia]. Chemistry for Sustainable Development, 1995, vol. 3, no. 1-2, pp. 43-55.

30. Mezhibor A.M., Rihvanov L.P. Biogeokhimicheskaya kharakteristika mkhov Polytrichum commune na territorii Urskogo khvostokhranilishcha v Kemerovskoy oblasti [Biogeochemical characteristics of moss Polytrichum commune in the territory of the Ursky tailing dump in the Kemerovo region]. Safety in the technosphere, 2016, vol. 5, no. 1, pp. 3-11.

31. Gustaytis M.A., Myagkaya I.N., Shcherbov B.L., Lazareva E.V. Zagryaznenie rtutyu okruzhayushchey sredy posle ekspluatatsii Novo-Urskogo zolotorudnogo mestorozhdeniya (Kemerovskaya oblast) [Environmental pollution by mercury after the operation of the Novo-Ursky gold deposit (Kemerovo region)]. News of Irkutsk State University. Seriya: Nauki o Zemle, 2016, vol. 18, pp. 14-24.

32. Bolgov G.P. Sulfidy Salaira. Urskaya gruppa polimetallicheskikh mestorozhdeniy [Salair sulfides. Urskaya group of polymetallic deposits]. News of the Tomsk Industrial Institute, 1937, vol. 58, pp. 45-96.

33. Myagkaya I.N. Mineralogo-geokhimicheskie osobennosti kontsentrirovaniya zolota organicheskim veshchestvom $v$ sisteme sulfidnye otvaly - torf ( na primere Urskogo khvostokhranilishcha, Kemerovskaya oblast, Rossiya ). Avtoreferat Dis. Kand. nauk [Mineralogical and geochemical features of gold concentration by organic matter in the system sulphide dumps - peat (on the example of the Ursky tailing, Kemerovo Region, Russia). Cand. Diss. Abstract]. Novosibirsk, 2013. $16 \mathrm{p}$.

34. Vazhenin I.G. Korni rasteniy kak bioindikator urovnya zagryaznennosti pochvy toksicheskimi elementami [Plant roots as a bioindicator of soil contamination level by toxic elements]. Agrochemistry, 1984, no. 2, pp. 73-77.

Received: 18 October 2018.

Information about the authors

Ekaterina A. Gorbatyuk, graduate student, National Research Tomsk Polytechnic University.

Natalia V. Baranovskaya, Dr. Sc, professor, National Research Tomsk Polytechnic University.

Vadim A. Zhdanov, student, National Research Tomsk Polytechnic University. 